\title{
Avaliadores Ad Hoc
}

Agradecemos aos avaliadores e avaliadoras ad hoc desta edição:

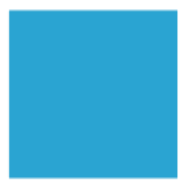

Revista

Extensão em Foco
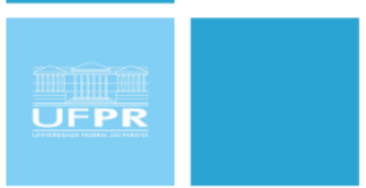

ISSN $2358-7180$

Alessandra Soares Furtado

Aline Machado Dorneles

Ana Lisiane Lopes da Silva

Ana Paula Santellano

Anahy Arrieche Fazio

Cláudia Beatriz Pio Borges

Eleonora Leguiçamo Centena Silva

Elisangela Luz da Costa

Fernanda Leite Nunes

Gabriel Vinicius Vian

Lais Francielle Costa da Rosa

Maria Fabiana Ferreira de Campos

Mélany Silva dos Santos

Raquel Fiori

Ronaldo Garcia

Sonia Martins de Oliveira Péres 